\title{
Author Correction: Climate-smart sustainable agriculture in low-to-intermediate shade agroforests
}

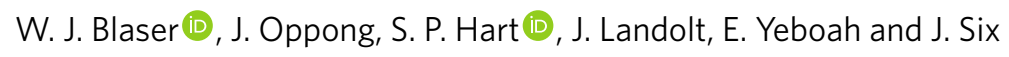

Correction to: Nature Sustainability https://doi.org/10.1038/s41893-018-0062-8, published online 15 May 2018.

In the version of this Article originally published, in the Methods subsection 'Agricultural production, pests and disease', the incorrect mirid bugs were referred to in the following sentence:

'We recorded the number of healthy and diseased cocoa pods and categorised diseased pods according to whether they had black pod (Phytophthora sp.) or other diseases (mostly mirid bugs Heleopeltis sp.).'

This sentence should have been: 'We recorded the number of healthy and diseased cocoa pods and categorised diseased pods according to whether they had black pod (Phytophthora sp.) or other diseases (mostly mirid bugs Sahlbergella singularis and Distantiella theobroma).'

This has now been amended.

Published online: 27 July 2020

https://doi.org/10.1038/s41893-020-0594-6

(C) The Author(s), under exclusive licence to Springer Nature Limited 2020 